\title{
V010 AZIMUTHAL AVO ANALYSIS OF A VERTICALLY FRACTURED RESERVOIR
}

\author{
BJØRN URSIN' and GEIR ULTVEIT HAUGEN ${ }^{2}$ \\ ' Norway University, NTNU, Department of Petroleum Engineers and Applied Geophysics, \\ 7034 Trondheim, Norway \\ ${ }^{2}$ Statoil Research Centre
}

\section{INTRODUCTION}

Good knowledge of fracture systems is of great importance in reservoir characterization. This requires mapping of fracture properties away from well locations, which, to significant distances, can only be done with seismic data. The presence of closely spaced vertical fractures in an isotropic background leads to a transversely isotropic medium with a horizontal symmetry axis (HTI), with some restrictions on the parameters. The anisotropy of an HTI model has a first-order influence on the amplitude versus offset and azimuth (AVO-A) response at an interface between two elastic media (Rüger and Tsvankin, 1995). Using 3-D P-wave reflection data, AVO-A analysis is particularly well suited for fracture characterization, because it provides local information about the anisotropy at the target horizon.

We have developed a new approximative expression for the scattering matrix at an interface separating two anisotropic media of arbitrary symmetry. This is done by treating the two media in contact as perturbations from an arbitrary chosen reference medium (Banik, 1987, Thomsen, 1993), in contrast to the average medium often used (Aki and Richards, 1980, Ursin and Haugen, 1996).

Using this model we will analyze the impact of fracturing in a model consisting of a shale over a vertically fractured sandstone, as shown in Figure 1. The shale is represented by a transversely isotropic medium with a vertical symmetry axis (VTI), and is parameterized in terms of the Thomsen (1993) parameters. The effect of the vertical fracturing on the elastic properties of the sandstone is calculated using effective medium theory (Nichols, Muir and Schoenberg, 1989, Haugen and Ursin, 1996). The vertically fractured sandstone can then be represented by an HTI medium, parameterized in terms of an isotropic background medium and two fracture parameters $\delta_{n}$ and $\delta_{t}$.

\section{NUMERICAL EXAMPLE}

The approximate expression for the $\mathrm{P}$-wave reflection coefficient was derived in the crack-normal plane (normal to the aligned cracks) and in the crack-strike plane (parallel to the cracks). Numerical results were computed for a VTI medium with parameters $\alpha_{1}=2.26, \beta_{1}=1.43, \rho_{1}=2.2, \epsilon_{1}=0.07$, $\delta_{1}=-0.05, \gamma_{1}=0.15$ over an HTI medium with parameters $\alpha_{2}=2.5, \beta_{2}=1.5, \rho_{2}=2.2, \delta_{n 2}=0.2$, $\delta_{t 2}=0.1$. The exact P-wave reflection coefficient is shown in Figure 2 as a surface plot with the approximations superimposed in the crack-normal and crack-strike plane as single curves. The reflection coefficients in the two symmetry planes are plotted to the right in Figure 2, together with the reflection coefficient for the VTI medium overlying the isotropic background medium. The reflection coefficient is increasing with offset in the crack-strike plane, while it is decreasing with offset in the crack-normal plane due to the influence of the cracks. Similar amplitude behavior has been observed in real seismic data by Lynn, Simon, Layman, Schneider, Bates and Jones (1995).

\section{ACKNOWLEDGMENT}

We would like to thank the "German-Norwegian Geoscientific Co-operation Project", sponsored by The Research Council of Norway and STATOIL, for financial support. 


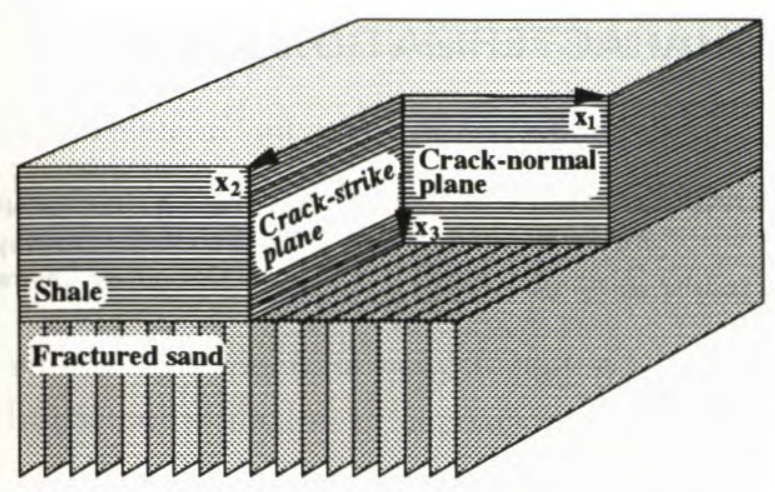

\begin{tabular}{|c|c|}
\hline & Shale \\
\hline $\begin{array}{c}\alpha_{01}, \beta_{01}, \rho_{1} \\
\epsilon_{1}, \delta_{1}, \gamma_{1}\end{array}$ & Thomsen parameters \\
\hline Vertically $f$ & actured sandstone \\
\hline$\alpha_{2}, \beta_{2}, \rho_{2}$ & Isotropic background \\
\hline$\delta_{n 2}, \delta_{t 2}$ & Fracture parameters \\
\hline
\end{tabular}

Figure 1: Model and parameterization
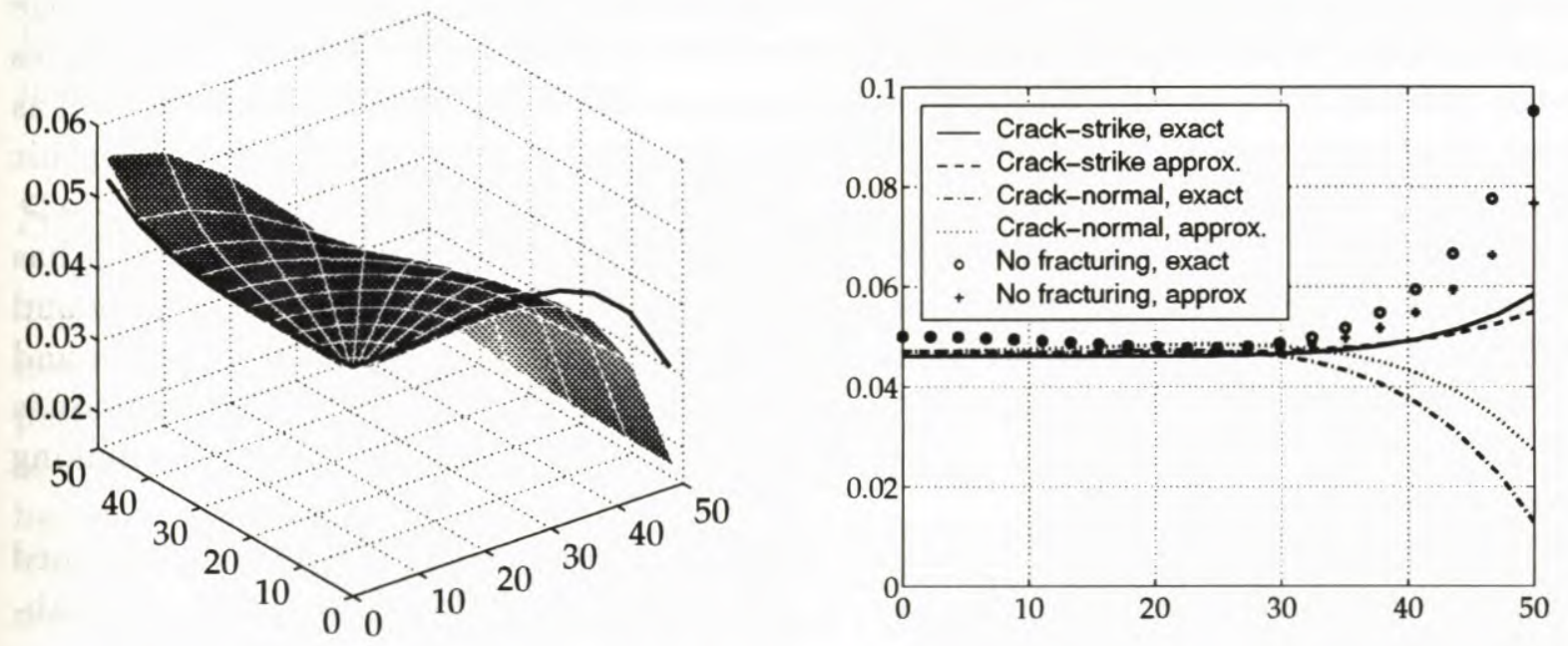

Figure 2: AVO-A response for the $\mathrm{P}$-wave reflection. The exact reflection coefficients with the approximations superimposed (left). The response in the crack-strike and crack-normal planes (right).

\section{REFERENCES}

Aki, K. and Richards, P., 1980, Quantitative Seismology, Theory and Methods, Vol. 1: W.H. Freeman and company.

Banik, N. C., 1987, An effective anisotropy parameter in transversely isotropic media: Geophysics, 52, 1654-1664.

Haugen, G. and Ursin, B., 1996, Elastic properties of rocks with fracture-induced anisotropy: SEG 'Special Volume on Seismic Anisotropy', in press.

Lynn, H. B., Simon, K. M., Layman, M., Schneider, R., Bates, C. R. and Jones, M., 1995, Use of anisotropy in $\mathrm{P}$-wave and S-wave data for fracture characterization in a naturally fractured gas reservoir, The Leading Edge, 14(8), 887-893.

Nichols, D., Muir, F. and Schoenberg, M., 1989, Elastic properties of rocks with multiple sets of fractures: 59th Ann. Internat. Mtg. of the SEG, Dallas, Expanded Abstracts, 471-474.

Rüger, A. and Tsvankin, I., 1995, Azimuthal vartiation of AVO response for fractured reservoirs: 65th Ann. Internat. Mtg. SEG, Houston, Expanded Abstracts, 1103-1106.

Thomsen, L., 1993, Weak anisotropic reflections, in Castagna, J.P. and Backus, M.M., Eds., Offset-dependent reflectivity - Theory and practice of AVO analysis: SEG, 103-111.

Ursin, B. and Haugen, G. U., 1996, Weak-contrast approximation of the elastic scattering matrix in anisotropic media: Pure and Applied Geophysics, in press. 